\title{
Neurokinin I receptor antagonism promotes active stress coping via enhanced septal 5-HT transmission Georg M Singewald ${ }^{1}$, Karl Ebner ${ }^{1}$, Nigel Whittle ${ }^{1}$, Francesco Ferraguti ${ }^{2}$ and Nicolas Singewald $* 2$
}

\author{
Address: ${ }^{1}$ Department of Pharmacology and Toxicology, Center for Molecular Biosciences Innsbruck (CMBI), University of Innsbruck, Austria and \\ ${ }^{2}$ Department of Pharmacology, Medical University of Innsbruck, Austria \\ Email: Nicolas Singewald* - nicolas.singewald@uibk.ac.at \\ * Corresponding author
}

from 13th Scientific Symposium of the Austrian Pharmacological Society (APHAR). Joint Meeting with the Austrian Society of Toxicology (ASTOX) and the Hungarian Society for Experimental and Clinical Pharmacology (MFT)

Vienna, Austria. 22-24 November 2007

Published: 14 November 2007

BMC Pharmacology 2007, 7(Suppl 2):AI doi:I0.I I86/I47|-22 I0-7-S2-A I

This abstract is available from: http://www.biomedcentral.com/I47I-22 I0/7/S2/A I

(C) 2007 Singewald et al; licensee BioMed Central Ltd.

Antagonists of the substance P (SP) preferring neurokinin 1 receptor $\left(\mathrm{NK}_{1}-\mathrm{R}\right)$ represent a promising novel class of drugs for the treatment of stress-related disorders including depression and anxiety disorders. The underlying neuronal mechanisms involved in the effects of these drugs, however, are poorly understood. By using in vivo microdialysis we observed increased SP, but reduced serotonin (5-HT) release during forced swim stress (FST) in the rat lateral septum (LS), a key area in processing emotions and stress responses. Acute administration of the selective high affinity $\mathrm{NK}_{1}-\mathrm{R}$ antagonist L-822429 injected either systemically or locally into the LS reversed the FSTinduced decrease in 5-HT efflux and facilitated active coping strategies during the FST. Increased active coping in the FST was attenuated by intraseptal $5-\mathrm{HT}_{1 \mathrm{~A}}-\mathrm{R}$ blockade with WAY100635, indicating that the behavioural effect during $\mathrm{NK}_{1}$ - $\mathrm{R}$ blockade is mediated by enhanced intraseptal serotonergic transmission acting on $5-\mathrm{HT}_{1 \mathrm{~A}}-\mathrm{R}$. Taken together, our findings identify the LS as an important brain area for the modulation of stress responses by the $\mathrm{SP} / \mathrm{NK}_{1}-\mathrm{R}$ system. $\mathrm{NK}_{1}-\mathrm{R}$ blockade resulted in behaviorally significant enhancement of 5-HT transmission. We show for the first time that this modulation does not necessarily involve interaction with neuronal firing at the cell body level of 5-HT neurons as previously postulated, but can be elicited in a terminal region of these neurons. 